\title{
4 The problem of intertheoretic comparisons
}

Let's start to address the issues that our argument from Chapter 2 raised. The most important such issue was the problem of intertheoretic comparisons-the question whether value can be compared across axiologies. Many people are sceptical about this. Edward Gracely considers a form of person-affecting utilitarianism and total utilitarianism. He asks:

is a small loss of utility as seen by a [person-affecting utilitarian] more or less important under that theory than a large loss of utility (involving lives not created) under total utilitarianism? I don't quite see how this question could be answered. ('ll refrain from saying that it is like comparing apples and oranges, but it is!) [...] There is no abstract scale of "wrongness" outside of the rank provided within a theory. $(1996,331)$

Similarly, John Broome is concerned with the fact that total and average utilitarianism have different 'units of value' $(2012,185)$ : wellbeing, and wellbeing per person respectively. He says:

We cannot take a sensible average of some amount of well-being and some amount of wellbeing per person. It would be like trying to take an average of a distance, whose unit is kilometres, and a speed, whose unit is kilometres per hour. Most theories of value will be incomparable in this way. $(2012,185)$

And in a similar vein, James Hudson imagines a person who has some credence in the pleasure-theory (its units being 'hedons') and in the self-realization-theory (its units being 'reals'). He argues:

What is the common measure between hedons and reals? Note that the agent, for all her uncertainty, believes with complete confidence that there's no common measure: she is sure that one or the other-pleasure or self-realization-is intrinsically worthless. Under the circumstances, the two units must be incomparable by the agent, and so there can be no way for her uncertainty to be taken into account in a reasonable decision procedure. $(1989,224)$

Other people have expressed similar doubts. ${ }^{78}$ In this chapter, I'll address these sceptics.

Let's recapitulate what the problem of intertheoretic comparisons is. In Chapter 1 , I defined ordinal and cardinal intertheoretic comparisons respectively as facts of the form

78 See Gustafsson and Torpman (2014) or Hedden (2016).

Ә Open Access. (C) 2021 Stefan Riedener, published by De Gruyter. (cc))BY-NC-ND This work is licensed under the Creative Commons Attribution-NonCommercial-NoDerivatives 4.0 International License.

https://doi.org/10.1515/9783110736199-004 
(C) the value-difference between outcomes $x$ and $y$, according to axiology $T_{i}$, is greater than the value-difference between outcomes $z$ and $t$, according to axiology $T_{j}$; and

(D) the value-difference between outcomes $x$ and $y$, according to axiology $T_{i}$, is $n$ times as great as the value-difference between outcomes $z$ and $t$, according to axiology $T_{j}$.

For most of what I'll say in this chapter, the difference between these kinds of facts doesn't matter. So to have a general term, let an intertheoretic comparison be a fact of either form. The problem of intertheoretic comparisons comprises three questions about these facts. First, there's a question about the meaning or criterion of identification of intertheoretic comparisons: what is it-or what would it be-for an intertheoretic comparison to hold? I've emphasised that this is unclear, both with respect to cardinal and ordinal comparisons. We might understand what it is for the value of a certain increase in wellbeing to be greater than the value of a certain increase in beauty, according to a welfare/beauty-theory. But unless more is said, it seems unclear what such comparisons across theories amount to. Yet suppose we know what it would be for intertheoretic comparisons to hold. There's then a second, object-level question about the actual intertheoretic comparison facts: do any intertheoretic comparisons hold; and if so, which of them do? Is the value of enjoying a bottle of Château Mouton Rothschild, according to a welfare-theory, say, as great as the value of a certain Paul Klee sketch, according to a beauty-theory-or as great as the value of a mediocre child painting, or of Leonardo's Lady with an Ermine? It seems unclear which such comparisons hold, or indeed whether any of them do. Yet suppose we know that some intertheoretic comparisons do hold, perhaps in some simple cases. There's then a third question about the grounds of these facts: what is it that grounds intertheoretic comparisons? It seems that axiologies themselves don't say how valuable certain things would be if certain other theories were true. So one might wonder what the basis of such comparisons can be. ${ }^{79}$

The sceptical challenge is to answer all of these questions. I've given an answer to the first question. I've provided an explication about what it would be for intertheoretic comparisons to hold. For such facts to hold would just be for certain $\mathrm{m}$-value facts to be the case. We arguably understand what it is for $\mathrm{m}$-value facts to be the case. And as the Basic Representation Theorem shows, given certain conditions, we can explicate cardinal comparisons in this manner. So this provides an answer to the question about meaning or identification.

79 I thank Adam Lovett for helping me see these three questions. 
However, for one thing, there are other accounts of intertheoretic comparisons. So before we can know that the prospect-explication provides the best reply to the question about what it is for intertheoretic comparisons to hold, we need to discuss these proposals. For another thing, even if the explication provides a sufficient answer to this particular question, the worries about truth and grounding still remain. They now simply arise for the m-value facts. A sceptic might agree that comparisons between the welfare- and the beauty-theory could in principle be understood in terms of m-value facts. But are there any nontrivial facts about which prospects are m-better than which in light of uncertainty about these theories? Or is the m-value relation radically incomplete, and $\boldsymbol{a}$ is at least as m-good as $\boldsymbol{b}$ only in the trivial case when it's at least as good on all axiologies with nonzero probability? And if there are nontrivial m-value facts, what are they? If there are no $\mathrm{m}$-value facts, then no intertheoretic comparisons actually hold. And if we don't know which m-value facts hold, we don't know which intertheoretic comparisons do. So the prospect-explication only defers the questions about the truth of intertheoretic comparisons. Similarly, a sceptic might even concede that some mvalue facts seem plausible. But what is it that grounds them? If we don't know what grounds the m-value facts, we don't know what ultimately grounds intertheoretic comparisons. The prospect-explication only defers the questions about the grounds of such comparisons. In order to have a more complete reply to scepticism, we must say more than the simple explication of such comparisons in terms of m-value facts.

So in the remainder of the chapter, I'll first discuss existing accounts of intertheoretic comparisons (Section 4.1). I'll argue that they're all unsatisfactory in one way or another, and that this corroborates the importance of the prospectexplication as an account of the meaning of intertheoretic comparisons. I then provide a minimal argument for the truth of some such comparisons (Section 4.2). This argument doesn't tell us which intertheoretic comparisons hold, or why they do. But if sound, it establishes that at least some such comparisons are true. I'll then introduce a novel account about what grounds these truths: constructivism about intertheoretic comparisons (Section 4.3). I argue that this view provides a compelling answer to the truth and grounding problems, or more generally to scepticism about intertheoretic comparisons. I'll end the chapter by discussing the implications of constructivism for the framework of this book (Section 4.4).

\subsection{Existing proposals}

Here are some existing proposals about intertheoretic comparisons. These accounts weren't explicitly proposed as theories of how axiologies compare. They 
were intended to account for comparisons between moral theories generally. But we can apply them to axiologies.

\section{Subjectivism}

Consider first a proposal that may seem particularly congenial to the decisiontheoretic approach of this book. We may call it 'subjectivism'. According to subjectivism, there are no objective facts about which prospects are m-better than which when you're axiologically uncertain. Rather, it all depends on you. You must have beliefs not only about the plausibility of axiological orderings, but also about the possible relative sizes of value-differences. You might have credence in the view that the pleasure-theory is true and that pleasure is comparatively valuable-i. e., that you ought to give a lot of weight to the pleasure- vis-à-vis the beauty-theory under uncertainty. Or you might have credence in the view that the pleasuretheory is true and that pleasure is of comparatively little value-i.e., that you ought to give little weight to the pleasure- vis-à-vis the beauty-theory. We might say you must believe in one or another version of the pleasure-theory, relative to the beauty-theory. If you have no such beliefs, there are no facts about which of your prospects are m-best relative to your state of uncertainty. And if you have such beliefs, these beliefs will ground your m-value facts. For example, if you have credence in the view that the pleasure-theory is true and that pleasure is comparatively valuable, then you ought to give the pleasure-theory a lot of weight vis-à-vis the beauty-theory in light of your uncertainty. So which of your prospects is m-best depends, radically, on which prospects you believe are m-best. If I understand her correctly, this is roughly the line that Amelia Hicks (2018) is taking. She says: 'there's no meaningful way of determining the "expected moral value" of an action. [...] However, [...] the decision-maker can still ordinally rank lotteries [...] and can assign utilities to the possible outcomes of their choice. It's those utilities-not the evaluations of actions provided by the competing moral theories-that determine which action has the highest expected utility for the decision-maker.' (2018, 172) As far as I see, she understands the utilities 'assigned [...] by the decisionmaker' as thoroughly subjective.

What's nice about subjectivism is that it parallels a standard, Humean interpretation of decision theory. A standard assumption in decision theory is that there are no substantive constraints on your preferences. You may prefer apples to oranges, pushpin to poetry, the destruction of the world to the scratching of your finger. Your preferences are fully rational as long as they satisfy the axioms. And plausibly, there's something to some extent parallel to this in the theory of axiological uncertainty. When we ask which of your prospects is 'm-best', we might 
be interested in (at least) two things. We might ask how you ought to evaluate your prospects given the credences your evidence warrants, and the intertheoretic comparisons that are in fact correct. Thus understood, EVM would figure as a substantive constraint on what credences you ought to have in which theories, how you ought to compare them, and how you ought to evaluate your prospects on the basis of these credences and comparisons. However, we might also ask how you ought to evaluate your prospects given the credences you happen to have, and the intertheoretic comparisons you personally make. Thus understood, EVM would be something like a coherence constraint on you. Both of these questions are interesting in distinct ways, as I'll elaborate in the next chapter.

What matters for now is that subjectivism can't be the whole story about intertheoretic comparisons. We may be interested in your beliefs about such comparisons. But there must also be an objectivist story about which of these beliefs are correct, or which comparisons actually hold. Most fundamentally, if there are no objective standards to distinguish reasonable m-value beliefs from unreasonable ones, we arguably can't speak of 'beliefs' in the first place. Belief presupposes a standard of correctness. So if subjectivism is the whole story, this reduces the question of intertheoretic comparisons to something like arational personal preference. The fact of an intertheoretic comparison holding between your theories would be a merely psychological fact about you. This would imply that if you have no such preference, the theory of axiological uncertainty can't possibly be action-guiding for you. And it would also imply that you could permissibly assume out of pure caprice that the value of pleasure would be 113.27 times greater if beauty also had value (i. e., that if you have $50 \%$ credence in the pleasure- and the pleasure/beauty-theories, you ought to 'judge' it equally m-good to bring about a certain pleasure while the pluralist theory is true and to bring about 113.27 pleasures of the same sort while the monistic theory is true). Indeed, it would mean that whenever you can permissibly have some nonzero credence in a theory on which one of your prospects is best, there's no basis for criticising you if you coherently 'judge' it to be m-best in light of your uncertainty. If you may have some nonzero credence in the Nietzschean view that you're an Übermensch for whom it's best to do what they please, there are no grounds for criticising your coherent 'judgment' that it's m-best for you to do what you please. But these are surely unfortunate results. We may ultimately be interested in your subjective credences and comparisons, and in whether you satisfy coherence constraints given them. But to assume that there aren't any objective criteria for evaluating your credences and comparisons seems very unsatisfying. We need a ground for saying that some intertheoretic comparisons are more reasonable than others. 


\section{Structural accounts}

So what objective criteria can there be for rendering some of your beliefs about intertheoretic comparisons plausible or true, and others implausible or false? Consider 'structural accounts'. According to these proposals, intertheoretic comparisons are grounded in general principles of rationality about how to normalize axiologies for evaluating prospects under axiological uncertainty. And these principles take into account only structural features of the theories-i.e., features of the theories' (ordinal or cardinal) betterness-ranking. Various principles of this kind have been proposed. For instance, Ted Lockhart $(2000,84)$ suggested the 'Principle of Equity among Moral Theories', according to which, in every choicesituation, the value-difference between the best and the worst prospect should be considered equally large according to all theories. Andrew Sepielli (2013a, 588) discussed (but didn't endorse) a variation of this principle, according to which the difference between the best and the worst conceivable prospect should be considered equally large according to all theories. Will MacAskill (2014, 89 ff.; also MacAskill et al. 2020a, ch. 4) suggested that the variance of theories should be considered equal, where the variance of a theory is a measure of how value is spread out over different prospects-viz., the average of the squared value-differences from the mean value of prospects. And infinitely many other structural proposals can be imagined beyond these.

If a structural comparison principle holds, your beliefs about intertheoretic comparisons can be false. They're false if they contradict the relevant principle. What's nice about these accounts is that they're metaphysically parsimonious. They ground intertheoretic comparisons fully in principles of rationality, and don't assume that there's an antecedent fact of the matter about how axiologies compare. Certainly, all of the above proposals have their specific problems. A problem of Lockhart's principle is that in making comparisons relative to choicesituations, it can rank a prospect as best even if it's worse than some available alternative on every axiology in which you have credence. ${ }^{80}$ A problem for Sepielli's proposal (as he notes) is that on many axiologies there are no best and worst conceivable prospects. And variance-normalisation faces some technical challenges in order to be well-defined. ${ }^{81}$ So it remains to be seen what the most plausible principle would be.

80 See Sepielli (2013a).

81 See e. g. MacAskill (2014, 104, fn. 94) for an indication of a challenge, and MacAskill (2014, $76 \mathrm{ff}$.) or MacAskill et al. (2020b) for a suggestion about how to address it. 
However, these accounts also face a general problem (at least if they're understood as fully general accounts of intertheoretic comparisons ${ }^{82}$ ). Insofar as we have intuitions about intertheoretic comparisons, they're sensitive to the content of axiologies. Suppose you're certain that pleasure has value, but uncertain whether beauty also has value, and that this is the only axiological uncertainty you have. We can then describe you as being uncertain between two axiologies, a monistic pleasure-theory and a pluralist pleasure/beauty-theory. Intuitively, it seems reasonable to compare your two theories in such a way that the value of pleasure is the same on both theories. After all, you're not uncertain about that value. You're only uncertain about the additional value of beauty. Purely structuralist accounts can't capture this content-based intuition. More specifically, the guiding idea of standard structural principles is that the axiological stakes should somehow be considered equal according to all theories. But insofar as we have intuitions about intertheoretic comparisons, it seems the stakes may be higher on some theories than on others. For instance, it seems that if both pleasure and beauty have value, the axiological stakes (overall, or in some choice-situations) are higher than if only pleasure has value. Again, purely structuralist accounts can't capture this intuition..$^{83}$ So the cost of their parsimony, it seems, is that they have implausible implications. Other things equal, we should prefer accounts on which intertheoretic comparisons are content-sensitive.

\section{Metaphysical accounts}

A range of accounts that are content-sensitive is what I'll call 'metaphysical accounts'. On these accounts, intertheoretic comparisons are not grounded in any facts about axiologically uncertain agents-i. e., in criteria of rationality for evaluation under uncertainty, or in epistemic principles, or actual beliefs of such agents. Rather, they're grounded in facts about values themselves, and are in this sense 'metaphysical facts' out there. The most explicit such account has been defended by Christian Tarsney $(2017 ; 2018 a)$. So let me consider his version. Tarsney starts from the comparison between the pleasure- and the pleasure/beauty-theory

82 MacAskill (2014) and MacAskill et al. (2020a) understand variance normalisation as applying only to a restricted class of theories, and hold that there are other grounds for intertheoretic comparisons besides this structural principle. I'll discuss such a hybrid approach in the context of 'metaphysical accounts' below. For now I'm considering whether structural accounts are plausible as general accounts of intertheoretic comparisons.

83 The same has been argued by MacAskill (2014, $134 \mathrm{ff}$.). 
I've just considered. To account for the intuitive intertheoretic comparisons between these theories, he suggests there are facts like

Value-Independence: the degree of value borne by a given unit of hedonic experience is independent of whether aesthetic goods are non-derivative valuebearers. $(2017,312)$

Put more simply, Value-Independence says that the value of pleasure is independent of whether beauty also has value. Tarsney understands this as holding independently of any facts about morally uncertain agents. As he understands it, it's a fact about value, quite like the fact that pleasure is valuable (if this is a fact). It's simply a counterfactual axiological fact, about how valuable pleasure would be if beauty also had value. ${ }^{84}$ I'll call a statement of this kind a value-counterfactual.

If such counterfactuals hold, they straightforwardly ground intertheoretic comparisons, and can thus render your beliefs about such comparisons false. This proposal can also straightforwardly account for our content-based intuitions. Value-Independence implies that the value of pleasure is the same on the pleasure- and the pleasure/beauty-theories. However, Tarsney's proposal also faces problems. To begin with, it seems unclear what value-counterfactuals should mean. Suppose the pleasure-theory is correct. What should it mean, say, that if beauty had value, the value of pleasure would be less than it actually is? And what should it mean, for that matter, that if beauty had value, the value of pleasure would still be exactly the same? Intuitively, we don't understand these counterfactual claims unless some further explication is given for them. And that's especially true concerning cardinal intertheoretic comparisons. We certainly have no unmediated understanding of the claim that if beauty had value, the value of pleasure would be half as great as it actually is, say. So it seems that the sceptical challenge of explaining what intertheoretic comparisons amount to really still remains-or has now simply been pushed back to the facts that allegedly ground them.

But suppose we have a sufficient intuitive grasp, or some helpful explication, of what statements like Value-Independence mean. There are then still worries about the object-level facts and their grounds. It's controversial that the universe contains any mind-independent axiological facts. But it seems quite an ontological burden to assume it should contain such counterfactuals. Suppose again that the pleasure-theory is true. Why should there be any fact of the matter about how the values implied by a false axiology compare to actual values? Why should the fabric of the universe contain not just standard axiological facts, but also counter-

84 See Tarsney (2017, 338 ff.). 
factuals about how valuable certain things would be if they were valuable-when in fact they aren't?

Tarsney gives an argument for the case of Value-Independence. He points out that even in expectational reasoning under purely descriptive uncertainty, we're commonly assuming that the value of certain facts is independent of certain other facts. To use his own example (2017, 314): suppose you can press a button, and are uncertain about whether doing so will save five people or kill ten, but certain that the only valuable thing is pleasure. If you decide not to press this button, this will be because you assume the value of pleasure doesn't depend on whether the button saves five or kills ten. You'll assume something like 'the value of pleasure is independent of whether the button will save five or kill ten'. And this latter proposition seems true. And Tarsney says 'there's no reason to expect that whatever story we tell about the truth of these propositions [in the context of purely descriptive uncertainty] will not extend straightforwardly' to value-counterfactuals (2017, 338). However, there is a story about these propositions that doesn't extend to value-counterfactuals. It's a standard story about value. Suppose the pleasuretheory is true, and that the value of an instance of pleasure depends only on its intensity and duration. And suppose these are necessary truths. Then the value of pleasure will be the same in all worlds in which the button will save five or kill ten. So the propositions relevant for empirical uncertainty can simply be grounded in standard first-order axiological facts. But this story doesn't even begin to explain why the value of pleasure would be equally strong in worlds in which beauty also had value. This is simply a different type of fact, which requires a different story about grounding. ${ }^{85}$

But let's even grant the truth of some value-counterfactuals like ValueIndependence-counterfactuals to the effect that the value of certain things wouldn't change if other things beyond them were valuable too. These are only the simplest counterfactuals, grounding comparisons between theories that share a common range of values, like our monistic and pluralist views. The existence of counterfactuals seems less and less plausible in more complex cases, or for axiologies that are more distinct. Take the comparison between the pleasure-theory, and a quasi-deontological theory on which there's value and disvalue only in

85 Tarsney might counter that there must be something that grounds the first-order axiological fact that the value of a certain instance of pleasure depends only on its intensity and duration, and that this will in turn also ground the value-counterfactual. But this needn't be so. This fact about pleasure might be a fundamental fact with no further grounds. Or it might be ultimately grounded in a fact that doesn't also ground value-counterfactuals-such as the fact that all sentient beings are morally equal. Again, objective mind-independent value-counterfactuals are a peculiar kind of fact, and require a distinct story about grounding. 
the following and contradicting of deontological reasons respectively-value in promises being kept or acts of beneficence being done, and disvalue in killings and robberies and lies. Suppose the pleasure-theory is correct. And consider a fact like 'if the quasi-deontological theory was true, the disvalue of breaking this promise would be as great as the actual disvalue of 25 hangnails'. The assumption that the world is populated by such more complex mind-independent counterfactuals quite definitely comes at considerable cost. And unless we have a positive story about what could ground them, or why we should assume them, we're now basically just asserting what the sceptics deny.

Tarsney acknowledges this last difficulty. He defends his metaphysical account only for theories with 'common content' (2018a, 327) or 'shared assumptions' (2018a, 332). So he concedes that 'comparability classes of normative theories may turn out to be few, small, and far between' (2018a, 336). But if this is the most we can hope for in terms of value-counterfactuals, metaphysical accounts are at best rather weak. They only explain intertheoretic comparisons for a relatively small subset of theories. To remedy this shortcoming, proponents of such an account might combine their approach with other methods of comparisons or alternative theories of uncertainty. They might hold that where metaphysical grounds are lacking, you ought to use a structural normalisation principle, or that in such cases you simply ought to evaluate your prospects in accordance with your favourite theory. ${ }^{86}$ But these extensions seem ad hoc. Suppose some intertheoretic comparisons are grounded in value-counterfactuals. Then, when no such counterfactuals hold, the theories are in an important sense incomparable. And this should arguably mean that no nontrivial m-value facts hold between prospects involving these theories. Why should we ignore this fundamental incomparability, and compare the theories through some convenient normalisation principle in decision-making? Or why should EVM then fail to apply, and My Favourite Theory suddenly come to be correct? Such claims don't seem to have any independent plausibility. They seem ad hoc manoeuvres, just designed to avoid the resulting widespread incommensurabilities suggested by metaphysical accounts of comparisons. Other things equal, we should prefer an account that delivers intertheoretic comparisons for a broader range of theories.

\section{Absolutist accounts}

Here's a fourth approach. I'll refer to proposals of this kind as 'absolutist accounts'. On these accounts, axiologies make statements about the absolute sizes

86 See Tarsney (2017, 338 ff.) or MacAskill et al. (2020a). 
of value-differences or heights of value-levels, and intertheoretic comparisons are grounded in these claims. The most prominent version of this idea employs fitting attitudes. On this proposal, there's an attitude or set of attitudes such that the fact that $x$ is better than $y$ means it's fitting to have these attitudes. For instance, it might mean it's fitting to be disappointed if you chose $y$. Furthermore, these attitudes come in degrees, and the greater the value-difference between $x$ and $y$, the stronger the attitudes that are fitting. A complete axiology must tell us not only which prospects are better than which, but also what absolute degrees of such attitudes are fitting. So it must tell you not only that $x$ is better than $y$, say, but also whether you ought to be slightly, or quite, or extremely disappointed, if you chose $y$. Consequently, there are infinitely many versions of any axiological ordering. There's the Keyed Up Pleasure-Theory, say, according to which only pleasure is valuable, and you ought to be extremely disappointed if you made someone suffer a hangnail. And there's the Calmed Down Pleasure-Theory, according to which only pleasure is valuable, but you ought to be only mildly disenchanted if you caused masses of people to be tortured. In this sense, axiologies make statements about the absolute sizes of value-differences or heights of value-levels. This has been suggested by Jacob Ross, who said: 'The scale of a value function can matter [...] quite apart from issues raised by evaluative uncertainty. [...] Two linearly evaluative theories can disagree [...] concerning the degree of disappointment that is warranted.' $(2006,765)^{87}$ If all of this is true, intertheoretic comparisons can be grounded in axiologies' claims about attitudes. So for it to be the case that the value-difference between $x$ and $y$, according to $T_{i}$, is greater than the value-difference between $z$ and $t$, according to $T_{j}$, is for the attitude it would be fitting to have towards $x$ and $y$ if $T_{i}$ is true to be stronger than the attitude it would be fitting to have towards $z$ and $t$ if $T_{j}$ is true. And whether or not this is so will depend on the theories we consider.

If absolutism is true, your m-value judgments can also be unreasonable. They're unreasonable if you have credences in implausible versions of axiologies. Moreover, absolutism might be able to ground a cardinal concept of value. As mentioned in Section 3.3 (on page 49), if $X$ is rich enough, an ordinal ranking of value-differences among outcomes in $X$ is enough to determine a utility function unique up to positive affine transformation representing that ordering. ${ }^{88}$ So suppose our set of outcomes $X$ is relevantly rich. And suppose we understand what it is for one attitude about the value-difference between $x$ and $y$ to be stronger than

87 Sepielli (2010, 181 ff.) discusses a related view.

88 See e. g. footnote 73. 
another about the difference between $z$ and $t$, for all outcomes in $X$. Then these rankings of attitudes imply a cardinal concept of value.

What's nice about absolutism is that it doesn't presuppose any extra facts, like value-counterfactuals, beyond the facts implied by our theories. It's facts implied by the axiologies themselves that ground comparisons. However, the account faces problems as well. To begin with, there's a general question about whether fitting attitude accounts of value are plausible-or whether it's plausible that for $x$ to be better than $y$ just is for a certain attitude to be fitting. There are worries about this. For instance, there's the 'wrong kinds of reasons' problem - the problem of demarcating the facts that render an attitude fitting from facts that perhaps speak in favour of having it, but don't render it fitting (such as a millionaire's offering you $£ 100$ for being pleased about a cup of mud). ${ }^{89}$ There’s the 'circularity problem'-the problem of finding a relevant set of attitudes that are indeed fitting to have towards what's valuable, and that aren't themselves evaluative judgments (on pain of circularity). ${ }^{90}$ And there's what we may call the 'fetishism problem'the worry that normative ethics and value theory should primarily be about what we ought to do, rather than about when we ought to be saddened or pleased, as the fitting attitude account suggests. ${ }^{91}$ The jury is still open on whether these problems can be solved.

But even if a fitting attitude account of value is plausible in general, there's a specific problem with the absolutist proposal, I think. To me at least, the core absolutist assumption seems dubious. There don't seem to be any facts about fitting absolute degrees of attitudes. If you're certain that the pleasure-theory provides the correct ordering, say, it seems meaningless to wonder whether everything is (linearly) more, or less, valuable than you thought, or whether it would be fitting for you to care (proportionally) more, or less, about everything. Suppose one person has Keyed Up Pleasure-Theory-attitudes and another has Calmed Down Pleasure-Theory-attitudes. They agree on all the kinds and relative strengths of attitudes. So whenever one of them is disappointed about $x$ rather than $y$ happening, then so is the other, and whenever one of them is five times as disappointed about this than about $z$ rather than $t$ happening, so is the other. But all of the first person's attitudes are stronger in absolute terms. On the absolutist proposal, at least one of them must be making a mistake, and misjudge the value of everything. But this seems implausible to me. It seems that the first person is more emotional than the second. And that's that.

89 This example is due to Crisp (2000, 459); see also D'Arms and Jacobson (2000).

90 See Bykvist (2009a) for this objection.

91 John Broome raised this objection in conversation. 
This isn't to say people's attitudes aren't criticisable. Usually, if you're devastated about someone's suffering a hangnail or feel only a slight disenchantment about an earthquake with 100'000 casualties, your attitudes are unfitting. But this is only because you'll usually have other attitudes that show you're getting the axiological ranking of outcomes wrong-considering a hangnail as on a par with a death, or a huge earthquake as on a par with a mosquito bite. If you had one of these attitudes, but had proportionally strong or weak attitudes about everything else, you wouldn't be misjudging anything. You'd be an exceptionally impassionate or equanimous person. And since your life might be better if you cooled down or warmed up, you might have prudential reasons to work on your mental states. But you wouldn't be getting any fact wrong. Or so it seems to me. ${ }^{92}$

\subsection{The Minimal Argument}

In short, none of these existing proposals seems to offer a convincing general answer to the problem of intertheoretic comparisons-or the questions about what intertheoretic comparisons mean, whether any of them are true or which of them are, and what grounds them. ${ }^{93}$ So let's turn back to the prospect-explication. Again, the prospect-explication (unlike arguably metaphysical accounts) provides a satisfying answer to the question of what it would be for an intertheoretic comparison to hold. But it doesn't yet tell us whether any such comparisons do in fact hold or which of them do, or what grounds them. So much of the challenge still remains: are there any nontrivial facts to the effect that some prospects are m-better than others? And what could ground these facts? I'll start with the first question (about truth) in the present section, and will turn to the second (about grounding) in the next.

Are there any nontrivial m-value facts? There's an analogue in social choice theory to the problem of intertheoretic comparisons-the problem of interpersonal comparisons of wellbeing. That's the question whether, or how, the wellbeing of one person compares to that of another. It's not a trivial question what the basis for such comparisons is, or what precisely they mean. But it's helpful to begin discussions in social choice theory with the observation that in everyday life we frequently make such comparisons. We say that healthy Silva is better off than sick Alba, that our money would benefit the latter more than the former, and

92 For a more thorough defence of this, and a more detailed exploration of the importance of things and of the limitations you face and the liberties you enjoy in adopting fitting attitudes towards everything, see e. g. Lovett and Riedener (2019).

93 For a further existing proposal, see e. g. Carr (forthcoming). 
so on. And in everyday contexts, such claims seem perfectly unproblematic. ${ }^{94}$ This doesn't prove that interpersonal comparisons are possible, nor does it tell us which comparisons hold, or what their basis is. But it strongly suggests something has gone awry if we deny their possibility altogether. It's helpful to begin a discussion of intertheoretic comparisons with a similar observation. It's very plausible that some nontrivial m-value facts, and intertheoretic comparisons, hold. Let's spell this out more precisely.

I've argued in the last chapter that (given our axiologies are vNM-conformable) m-value plausibly satisfies Transitivity, Independence and the Pareto Condition. I mentioned that Continuity is false if some axiologies compare in a lexical way. But if there are such axiologies, then intertheoretic comparisons are in any case possible. And barring such axiologies, Continuity seemed plausible too. So for present purposes, let's assume that the m-value facts satisfy Transitivity, Independence, Continuity and the Pareto Condition. If they do, we can give the Minimal Argument:

(O) The m-value facts aren't radically incomplete;

(P) if the m-value facts aren't radically incomplete (and satisfy Transitivity, Independence, Continuity and the Pareto Condition), some intertheoretic comparisons hold; therefore

(Q) some intertheoretic comparisons hold.

Here's what I mean by this. Say that two prospects $\boldsymbol{a}$ and $\boldsymbol{b}$ in $\mathcal{Q}$ are in the same possibility-space if they assign non-zero probability to the same axiologies, i. e., if for all $i$ in $I, \boldsymbol{a}$ is in $\mathcal{Q}^{i}$ if and only if $\boldsymbol{b}$ is in $\mathcal{Q}^{i}$. And say that a binary relation $\geq$ on $\mathcal{Q}$ is radically incomplete if for all $\boldsymbol{a}$ and $\boldsymbol{b}$ in the same possibility space,

$$
\boldsymbol{a} \geq \boldsymbol{b} \quad \text { only if } \quad H_{i}(\boldsymbol{a}) \succeq_{i} H_{i}(\boldsymbol{b}) \quad \text { for all } i \text { in } I \text { with } \boldsymbol{a} \text { and } \boldsymbol{b} \text { in } \mathcal{Q}^{i} .
$$

Intuitively, if the m-value relation is radically incomplete, then whenever there's one theory with nonzero probability according to which $\boldsymbol{b}$ is better than $\boldsymbol{a}, \boldsymbol{a}$ isn't at least as m-good as $\boldsymbol{b}$. (0) says this is not so. It says that sometimes a prospect $\boldsymbol{a}$ is at least as m-good as another prospect $\boldsymbol{b}$ even if, according to some axiology with nonzero probability, it's worse.

This is very plausible. First of all, it simply seems highly intuitive. Take a standard welfare-theory, and a human-welfare-theory, according to which one prospect is better than another if and only if it leads to more human wellbeing, while the wellbeing of non-human animals is irrelevant. Suppose the anthropocentrism of the latter theory makes it very implausible, or that these theories

94 This is observed e. g. by List (2003, 229). 
have probabilities of $99 \%$ and $1 \%$ respectively. And consider two prospects that differ in terms of the welfare of a million non-human mammals and one human being:

$\boldsymbol{a}$ all the non-human mammals live very long, happy and painless lives but the person suffers from a hangnail; and

b all the non-human mammals live very long lives full of torture and agony, but the person doesn't suffer from the hangnail (and lives otherwise as in $\boldsymbol{a}$ ). ${ }^{95}$

The welfare-theory says that $\boldsymbol{a}$ is better than $\boldsymbol{b}$; the human-welfare-theory says the opposite. Intuitively, $\boldsymbol{a}$ is clearly m-better than $\boldsymbol{b}$. If you faced these options, under the abovementioned state of uncertainty, surely you'd judge it m-better to choose $\boldsymbol{a}$ in light of your uncertainty. But if $\boldsymbol{a}$ is m-better than $\boldsymbol{b}$, that's enough to establish that the m-value facts aren't radically incomplete. Similar intuitions hold also for less closely related views. Take the pleasure-theory and the beautytheory. Suppose the aestheticism of the latter makes it very implausible, or that these theories have probabilities of $99 \%$ and $1 \%$ respectively. Now consider two prospects that differ in terms of the welfare of a million human beings and the existence of a little Paul Klee sketch:

c all the people live very long, happy and painless lives but the Klee sketch is destroyed; and

d all the people live very long lives full of torture and agony, but the sketch isn't destroyed.

The pleasure-theory says that $\boldsymbol{c}$ is better than $\boldsymbol{d}$; the beauty-theory says the opposite. Again, intuitively $\boldsymbol{c}$ is clearly m-better than $\boldsymbol{d}$. Denying (0), or holding that even in such extreme cases no positive m-value fact holds, seems very counterintuitive.

But it's not just that. Accepting radical incompleteness would arguably involve a considerable theoretical cost. In Chapter 1 I've argued that $\mathrm{m}$-value is practically very important. Basically all of our decisions are decisions in the face of axiological uncertainty. If according to the correct theory of $\mathrm{m}$-value, the $\mathrm{m}$-value facts are radically incomplete, this suggests that in few of our decisions it's better to do one thing rather than another in light of our uncertainty. Denying (0) amounts to a very radical normative or evaluative scepticism in practice. Consequently, it's in fact something that even many sceptics want to avoid. Few sceptics simply concede that the $\mathrm{m}$-value relation is radically incomplete. Instead, they

95 I thank William MacAskill for suggesting this example to me. 
generally endorse alternative theories of m-value that satisfy Completeness-such as My Favourite Theory. ${ }^{96}$ A denial of (O) seemed unattractive even to sceptics.

What these sceptics may want to deny is $(\mathrm{P})$. The general idea behind this premise is that intertheoretic incomparability should give rise to incompleteness in the m-value relation. The just-mentioned sceptics deny this. They think that if no intertheoretic comparisons hold, the m-value relation might still be complete-e.g. as according to My Favourite Theory. This inference from scepticism to My Favourite Theory is in fact questionable. When we determine the value of a prospect, absent any incomparability, it's very implausible that we can focus on probabilities only and ignore the values of outcomes. Both probabilities and values determine the goodness of prospects. That's the basic tenet of decision theory, in its simplest form. So if there is incomparability in values, there's no reason why we could ignore that, and just focus on probabilities. My Favourite Theory seems like an ad hoc solution for sceptics to avoid the radical incompleteness of $\geq_{m}$. That's another drawback of this view.

However, for present purposes, we needn't rely on this general argument. I've presupposed that the m-value facts satisfy Transitivity, Independence, Continuity and the Pareto Condition. And at least if that is true, (P) can plausibly be treated as a matter of explication, parallel to the prospect-explications of the last chapter. If these conditions hold, and the m-value facts aren't radically incomplete, there are relevantly unique sets of utility functions representing our axiologies, such that a prospect is $\mathrm{m}$-better than another if and only it has a greater expected utility according to all functions in this set. So again, our axiologies will weigh in a particular way against each other to determine the m-value facts. And in the sense that's relevant for us, this means they are comparable. We can say that the value-difference between $x$ and $y$, according to $T_{i}$, is at least $n$ times as great as the value-difference between $z$ and $t$, according to $T_{j}$, if that is true on all utility functions in our set. The technical details of this needn't concern us now. I'll explore them in Chapter 6. What matters for now is that, given the other axioms, the weak and mundane fact that the m-value relation isn't radically incomplete already implies that our axiologies weigh in a particular constant way against each other to determine m-value. It means some intertheoretic comparisons hold.

So, at least given Transitivity, Independence, Continuity and the Pareto Condition, the Minimal Argument seems sound. Again, it establishes a very weak conclusion. The argument doesn't say which comparisons hold, or why they do. Nor does it imply that all or even most axiologies are comparable. (Q) only says that

96 See e. g. Gracely (1996) or Gustafsson and Torpman (2014); also Tarsney (2018a, 338 ff.). 
some intertheoretic comparisons hold. Or as in the social choice context, it suggest that something has gone wrong if we deny their possibility altogether. Let's see where we get from here.

\subsection{Constructivism}

In principle, the prospect-explications, and the axiomatic approach of this book, are compatible with different stories about the grounds of $\mathrm{m}$-value facts. My overall argument doesn't depend on the specific view I'll now outline. But I think the following story is plausible. If some nontrivial $\mathrm{m}$-value facts hold, they must either be brute fundamental facts, or there must be a more fundamental kind of facts that grounds them. And m-value facts don't seem to be brute. Plausibly, there are some fundamental normative facts, such as that we're all morally equal, or that pain is bad. But facts about how you ought to evaluate your prospects under uncertainty are highly complex. It seems implausible that they should be fundamental. ${ }^{97}$ More plausibly, there's a more fundamental set of facts that grounds them. Or in short, the Minimal Argument suggests that there must be a class of facts that grounds intertheoretic comparisons. So what can this be, if intertheoretic comparisons aren't entirely subjective, and if there's no structural normalisation principle, no independent metaphysical fact, or no absolutist value facts that makes certain comparisons correct? Here's the proposal I find most attractive.

\section{The core idea}

The key idea is that intertheoretic comparisons are grounded in epistemic norms. There are epistemic norms that are plausible independently of the problem of intertheoretic comparisons. We can understand them as holding prior to such comparisons, and grounding them in a constructivist manner.

To illustrate what I mean, let me give some examples of the kind of norms I have in mind, and of how they can be constraining. One type of norm might be synchronic norms concerning your credence distribution at any time. A good candidate of this kind is

Simplicity: ceteris paribus, you should favour simpler credence distributions over more complex ones. ${ }^{98}$

97 See Tarsney (2018a, 327) for a related thought.

98 I thank Christian Tarsney for suggesting this principle to me. 
It's difficult to spell out precisely what 'simple' means. But we arguably have an intuitive understanding of it. So suppose Simplicity holds. Then it constrains the intertheoretic comparisons you can reasonably make. The credence distribution on which the value of pleasure is equally great on the pleasure- and the pleasure/beauty-theory is arguably simpler than that on which their ratio is 113.27 , or anything other than 1 . So if Simplicity is true, and if you have no reason to believe anything else, you should favour this simple comparison. More generally, you should ceteris paribus believe that the values shared by overlapping theories are equally great on both. You should make m-value judgments that imply intertheoretic comparisons of this form.

Other candidate norms are diachronic ones concerning the evolution of your credences over time. Consider epistemic conservatism, the idea that you shouldn't change your beliefs in the absence of any reason to do so. ${ }^{99}$ An implication of this idea for how to deal with new evidence might be put as

Conservatism: if you encounter new evidence, then of the possible changes to your credences that accommodate this evidence you should ceteris paribus favour less radical over more radical ones.

This norm too constrains your intertheoretic comparisons. Suppose you've so far believed in the pleasure-theory, but now encounter some evidence for the value of beauty. The least radical way to accommodate this evidence is to adopt some positive credence in the value of beauty, but to leave your beliefs about pleasure unchanged. Any comparison on which the value of pleasure is greater, or smaller, on the pluralist theory than on the monist one would suggest you may so far have misjudged that value. It would mean you'd have to change your mind about the value of pleasure if you came to accept the value of beauty besides it. But epistemic conservatism says there's a presumption in favour of not changing your mind, or believing you were wrong, absent any positive grounds. So if Conservatism is correct, and if you have no positive countervailing reason, you should believe that the value of pleasure is equally great on both theories. More generally, you should ceteris paribus not change your beliefs about some given values in the face of evidence for additional values besides them.

As a third candidate norm, consider

Coherence: ceteris paribus, you should favour more coherent credence distributions over less coherent ones,

99 See e. g. Chisholm (1980), Kvanvig (1989) or McCain (2008) for versions of this view. 
where coherence is understood roughly as the degree to which your beliefs are mutually supportive. Such a norm can also constrain your intertheoretic comparisons. It can do so, for instance, if you have an error theory about why you might have been mistaken about value. Suppose again you've so far believed in the pleasure-theory, but now encounter some evidence for the value of beauty. And suppose you have a belief, conditional on the pluralist theory, about why you've long missed its truth. For example, you believe that if beauty also had value, you'd simply have been insensitive to its particular worth. This explanation suggests that even if the pluralist theory is true, you've never made any mistake with respect to the value of pleasure. So it arguably coheres best with the intertheoretic comparisons on which the value of pleasure is the same on both theories. Any alternative credence distribution would suggest that you haven't just overlooked the value of beauty, but also misjudged the value of pleasure. And this wouldn't square well with your own simple error theory.

These norms are only examples. Roughly, they suggest that absent any explanation, you shouldn't assume that you've always systematically and radically misjudged the magnitude of everyday paradigm values. And they imply you should more readily assume you may have misjudged some values if you have an explanation for why and how you may have done so, or if these values are less mundane and pervasive. I take it that this is plausible. But Simplicity, Conservatism and Coherence might be false, ${ }^{100}$ or not quite correct as I've stated them, or there might be other and more important norms besides them. And there are of course questions about how to best understand even these principles, and further work to do to prove that they'll successfully constrain our judgments. ${ }^{101} \mathrm{My}$ aim is not to argue for these precise norms. I'm happy if it's plausible that some such epis-

100 For instance, Simplicity resembles common principles of Objective Bayesianism, such as the Principle of Indifference or the Principle of Maximum Entropy (see e. g. Keynes 1921, ch. 4; Jaynes 1957a, 1957b; Williamson 2010). These principles face well-known challenges (e. g., representation dependency; see e. g. von Kries 1886, or Keynes 1921, ch.4). Simplicity might face similar challenges. See e. g. Foley (1983), Christensen (1994) or Vahid (2004) for objections to epistemic conservatism.

101 One question will be whether agents following these principles will converge on specific judgments, rather than end up in an infinite process of ever-changing judgments, or oscillation between different equilibria. The discussion here might benefit from the existing literature on convergence in Bayesianism (see e. g. the theorem by Doob 1971). More generally, and as already indicated in footnote 100, there's a somewhat parallel debate about the most plausible principles of Objective Bayesianism (see e. g. Williamson 2010). There's also a debate about how to best understand the method of reflective equilibrium (see e. g. Elgin 1996). Important progress on our present questions might be made by building on these debates. 
temic norms hold that can successfully constrain the intertheoretic comparisons or m-value judgments you can reasonably make.

If that's so, we can invoke a form of constructivism to ground intertheoretic comparisons, or judge some of your subjective beliefs about them as false. We can understand truth about intertheoretic comparisons as the outcome of ideally reasonable deliberation-in terms of principles like the above-about which of your prospects are m-best in light of your axiological uncertainty. By comparison, consider the view that truth in first-order moral theory is simply the result of an ideal process of systematising our pre-theoretic moral beliefs. ${ }^{102}$ On this view, it's not that there's some independent Platonic realm of moral facts, and that norms of simplicity and coherence are best at guiding us towards it. Rather, the principles are first, and 'truth' is simply the outcome of the principles. We can invoke a similar kind of constructivism about intertheoretic comparisons. On this view, principles like Simplicity, Conservatism and Coherence are not justified in virtue of their guiding us towards an independent realm of $\mathrm{m}$-value facts or intertheoretic comparisons. Rather, they help constitute this realm. So this provides an answer to why some m-value facts or intertheoretic comparisons hold. It's not because of mind-independent metaphysical facts about how theories compare, or how great certain values would be if they existed. It's simply because of facts about how to respond reasonably to axiological evidence or have reasonable axiological beliefs. Ultimately, we might say, it's because of facts about us-about why we might have been wrong about axiology, and by how much and in what way, and so on.

\section{Applications, clarifications, and worries}

The case of the pleasure- and the pleasure/beauty-theories was exceptionally simple. So let's see how these epistemic principles could be applied in more complex cases. Suppose you've long believed in the pleasure-theory. But you have recently come to doubt it, and now slightly prefer the above-mentioned quasideontological theory on which there's value and disvalue only in the following or contradicting of deontological reasons respectively. What intertheoretic comparisons (or m-value judgments) would it be most reasonable for you to make?

Simplicity might tell you to look at prospects or outcomes that both of these theories deem good or bad. That might be acts of beneficence, say, which both lead to pleasure and to the following of some deontological reason. So Simplicity might

102 For classic (though more specific) versions of this view, see e.g. Rawls (1980), Korsgaard (1996) or Scanlon (1998). 
favour a credence distribution on which the value of such acts of beneficence is the same on both views.

But these values might be comparatively inconsequential within the quasideontological theory. That theory might say it's much worse to lie or steal or break promises, say, than to omit acts of supererogatory beneficence. So this simple comparison might imply that the relevant other values of this theory are massively greater than the value of standard acts of beneficence on the pleasuretheory. It thus constitutes a radical departure from your original beliefs. You've so far believed that there are no such extra quasi-deontological values. But on this comparison, there might be extremely great values of this kind. So the comparison suggests you might have misjudged massively the disvalues of promise-breaking, stealing or lying. Conservatism might thus favour a credence distribution on which the value of beneficence is greater on the pleasure-theory than on the quasi-deontological axiology. Such a comparison suggests you might have misjudged the value of beneficence, as well as the other quasi-deontological values. But it doesn't imply that you might have been so horrendously wrong about the latter. So the overall extent to which you represent yourself as possibly having misjudged values might be smaller on this latter comparison than on the former. And these implications of Conservatism might have to be balanced against those of Simplicity.

But suppose you also have some pertinent non-normative beliefs. According to standard deontology, it's ceteris paribus more important not to harm people than to positively benefit them. So on the quasi-deontological axiology we're considering, the disvalue of harming someone is greater than the value of proportionally benefiting them. And if this theory is true, there must arguably be some explanation for why you always got this wrong, believing as you did in the pleasuretheory. Suppose you have a belief about that. Suppose you believe that conditional on the quasi-deontological theory, you always mistook these quasi-deontological values and disvalues for deontic constraints against harming that have nothing to do with axiological values. This suggest you always greatly underestimated the disvalue of harming. Thus Coherence might favour intertheoretic comparisons on which you always knew the value of beneficence-or on which your two theories agree on this-but on which it's of comparatively great disvalue to harm if the quasi-deontological theory is true. But you might have some other explanation. Suppose you believe that conditional on the quasi-deontological theory, it was because you never received much beneficence in your childhood that you turned beneficence into a sort of idol. This suggest you always greatly overestimated the value of beneficence. So in this case, Coherence might favour comparisons on which you always knew the disvalue of harming-or on which your two theories agree on that-but on which it's of comparatively little value to benefit if 
the quasi-deontological theory holds. And whatever explanation you prefer, the implications of Coherence might again have to be balanced against those of Simplicity and Conservatism.

All of this is only a rough sketch of how norms like Simplicity, Conservatism and Coherence could operate in more complex cases. But it suffices to indicate that applying these norms can be fruitful. In particular, they seem to give us more resources to make intertheoretic comparisons than metaphysical accounts allow. Our norms have non-trivial implications for the comparison between the pleasureand the quasi-deontological theory in light of our prior beliefs, say, or our beliefs about our beliefs in the form of an error theory. These resources don't seem available for metaphysical accounts. Indeed, as I've suggested, it's unclear what a mind-independent basis for intertheoretic comparisons between such theories could be. So there's reason to be more optimistic, I think, that at least some intertheoretic comparisons hold not only for 'few and far between' theories.

One feature of the above principles is worth noting. In light of Simplicity, Conservatism and Coherence, the relevant m-value facts might be different from person to person. Most notably, it depends on your priors which intertheoretic comparisons effect the least radical changes in your credences. So in this sense, if the above principles hold, there won't be a universal truth of the form 'the value-difference between outcomes $x$ and $y$, according to the pleasure-theory, is greater than the value-difference between outcomes $z$ and $t$, according to the quasi-deontological theory'. Whether or not this statement is true will be different from person to person.

One might be worried about this, for at least three reasons. First, one might think it implies that the truth of certain propositions-i. e., intertheoretic comparisons-can be relative to individuals. And one might find such alethic relativism dubious. However, our constructivism doesn't imply such relativism. Recall that on the prospect-explication, the fact that certain intertheoretic comparisons hold among your theories only means that certain prospects are m-better than others in light of your uncertainty. So if different m-value facts hold for different people who are uncertain about the same axiological orderings, we needn't understand this as meaning that one and the same proposition-about how two specific theories actually compare-is true for one person but false for another. We can understand it as meaning that it's reasonable for these people to believe in different versions of these orderings. Talk of 'different versions' of the pleasuretheory, say, doesn't presuppose absolutism. We can assume (pace Ross 2006, 765) that the versions differ in nothing 'apart from issues raised by evaluative uncertainty'. On this assumption, the only difference between the pleasure-theory ${ }_{1}$ and the pleasure-theory 2 , say, concerns which prospects are m-better than which in light of uncertainty about them. So their difference will only be apparent relative 
to some fixed version of the pleasure/beauty-theory, say. And two people who have the same credences in the same orderings and for whom the same m-value facts hold cannot be further distinguished-as they can on absolutism, where all of one person's theories might be keyed up versions of the theories of the other. But all of this seems plausible. Different $m$-value facts can be true relative to different people, insofar as it may be reasonable for them to believe in what are, in this thin sense, different versions of their theories. There's nothing dubious or problematic about that. Or at any rate, it certainly doesn't imply alethic relativism.

By the same token, the constructivism we're invoking is less radical than it might sound. The epistemic norms ultimately determine what's m-best for you in light of your uncertainty, say, between the pleasure-theory and the quasideontological view. And in this sense they determine how your axiologies compare. But they needn't imply a unique truth about this comparison. So again, we might say they just determine what 'versions' of your theories you should have credence in. And that's to say, they function like we all think epistemic norms function-determining what propositions or theories you should believe. When they imply you should have credence, say, in versions of these theories on which the value of beneficence is equally great on both, this isn't because this value really is equally great. And it doesn't imply it is equally great in some Platonic realm independent of axiologically uncertain agents. It simply means beliefs in such versions is most reasonable in light of your evidence and priors.

Second, one might worry that such prior-dependency renders constructivism overly subjectivist. Suppose you started with sufficiently crazy priors-e. g., certainty in the Nietzschean axiology on which it's best if you do what you please. Couldn't this still mean that it will eventually be m-best if you do as you please? And isn't this still very unfortunate, meaning the correctness of your m-value judgments remains highly sensitive to your personal doxastic quirks?

There's a number of points in reply to this. To begin with, the present theory is nowhere nearly as subjectivist as the subjectivism considered in Section 4.1. On that theory, there were no constraints whatsoever on your comparisons. This meant that if you permissibly have some nonzero credence in the Nietzschean axiology there are no grounds for criticising your coherent 'judgment' that it's mbest for you to do as you please. Indeed, it meant that this couldn't even be regarded as a judgment. On constructivism, as far as I've said, there may be no constraints on your very first credence distribution among axiological orderings. But there are always at least some constraints on your comparisons (e. g. Simplicity and Coherence). And the more evidence you gather, the more such constraints will apply to you (e.g. in light of Conservatism). So it's not the case that any such nonzero credence would allow you to make Nietzschean m-value judgments, let alone that those wouldn't even be judgments. Next, nothing about constructivism 
implies that there couldn't also be constraints your very first credence distribution among axiological orderings. Indeed, perhaps Simplicity is such a constraint: perhaps if you have no relevant evidence, it's simpler to have equal credences in both the pleasure- and the quasi-deontological theory. Or perhaps there are other, more specific such principles. ${ }^{103}$ Now admittedly, such constraints may not always uniquely determine reasonable prior credences. So there might always be some discretion for subjectivity. But finally, that's true on every standard theory of rational degrees of belief. Even the most orthodox Objective Bayesians think that there aren't always uniquely determined rational prior probabilities. ${ }^{104}$ So it's unclear why the degree of subjectivity that remains on constructivism should in any way be implausible.

Third, one might worry that our dependency on priors makes interpersonal intertheoretic comparisons impossible. Suppose Albert thinks it would be m-better for us to sacrifice some equality to increase overall pleasure, while Lydia thinks it would be m-better not to. Intuitively, in some such cases, there's more at stake in terms of (m-)value for one person than for the other. And the truth of such interpersonal comparisons may be important in practice: we might need them, say, to make reasonable decisions from the point of view of society, aggregating individuals' m-value judgments. So there are analogous questions here as in the case of intrapersonal intertheoretic comparisons, about what these interpersonal comparisons of m-value mean, about which such comparisons hold, and what grounds them. Structural, metaphysical and absolutist accounts won't have any problems here. Their principles will apply across individuals just as for a single individual. But one might think the version of constructivism I've sketched faces problems due to the prior- and person-relativism it implies.

However, I don't think it does. The most natural approach for constructivism is to take the perspective of society, or perhaps a neutral decision-maker, and apply principles like Simplicity and Coherence again. Suppose Albert is certain of the pleasure-theory, while Lydia is certain of a pleasure/equality-theory on which both pleasure and equality are intrinsically good. From the point of view of society, the simplest assumption seems that they agree about the value of pleasure, but disagree about whether equality has value too. So this simplicity might ground the correct comparison between their judgments. Or suppose Albert believes in the pleasure-theory, while Lydia believes in the quasi-deontological theory on which there's an extra gravity to unjust or discriminatory harms. There might be some extra facts that help us make comparisons in light of Coherence. For in-

103 See footnote 100.

104 See Talbott (2016, sec. 4.2). 
stance, perhaps both have plenty of experience of innocent pleasures, but only Lydia has first-hand experience of injustices. This might suggest that, conditional on Lydia being right, Albert simply underestimated the disvalue of injustices due to his lack of experience. And it might suggest that, conditional on Albert being right, Lydia overestimated the disvalue of such injustices precisely because of her personal involvement in them. In short, it might suggest that they agree about the value of pleasure, but disagree about the disvalue of these inequalities. The more general point is that there's no principled reason why our or similar principles couldn't ground interpersonal comparisons too.

\subsection{Conclusion: constructivism and EVM}

If all I've said is correct, we've answered the three sceptical worries. The prospectexplication explains what it is, or what it would be, for an intertheoretic comparison to hold. For a certain such comparison to hold would just be for certain mvalue facts to be the case. This leaves open whether any such facts are the case, or which of them are, and what grounds them. The Minimal Argument suggests that some m-value facts must hold, and that there must be some further set of facts that grounds them. But it still doesn't tell us which m-value facts hold, or in what they ground. Constructivism is at least one plausible story to fill this gap for my overall argument. It suggests facts about $\mathrm{m}$-value or intertheoretic comparisons are grounded constructively in epistemic norms. And so it's these norms, together perhaps with your priors, that determine which comparisons hold. In other words, we can answer radical scepticism. It's implausible that the m-value facts must be radically incomplete, or the idea of EVM fundamentally flawed in light of the problem of comparisons.

A follow-up question relevant for the framework of this book is whether given constructivism (and given our axiologies are vNM-conformable) it's plausible that the m-value facts satisfy Continuity and Completeness. Take Continuity first. As indicated in Section 3.2, m-value isn't continuous if some axiologies compare in a lexical way. So is it plausible, on constructivism, that some axiologies compare lexically? It doesn't seem so. Intuitively, credence distributions that don't feature lexical dominance seem simpler than credence distributions that do. And they'll cohere better with standard simple error theories. If you've so far believed in the pleasure-theory, but now have evidence for the value of beauty, it seems plausible that if beauty had value you'd simply have been insensitive to its worth. This explanation suggests there's nothing special about beauty or pleasure. Their being valuable are equal axiological possibilities. The idea that one of them is potentially infinitely more or less important than the other would lack any explanation, 
or not cohere well with this error theory. Constructivism suggest that m-value satisfies Continuity, or at least doesn't violate it due to lexical intertheoretic comparisons.

So consider Completeness. As indicated, m-value isn't complete if some axiologies aren't fully commensurable. So is it plausible, on constructivism, that some axiologies are to some extent incommensurable? It seems so. Perhaps for some axiologies and some belief-sets, it's plausible that the axiologies compare in a precise way. Perhaps it's plausible that if you have no relevant error theory, you should consider the value of pleasure to be precisely equally great on the pleasure- and the pleasure/beauty-theories. But it seems implausible that no matter what other beliefs you have, there's a precise specific number $n$ of hangnails, such that you should consider the disvalue of breaking a particular promise, according to the quasi-deontological theory, as equally great as the disvalue of suffering $n$ hangnails, according to the pleasure-theory. Among other things, any precise number $n$-or any precise comparison-would seem to some extent arbitrary or inexplicable, and thus less fully coherent with the rest of your beliefs. It can sometimes be most reasonable for you to assume that some axiologies compare only roughly. Sometimes, you should consider the disvalue of breaking a particular promise, according to the quasi-deontological theory, as being determinately greater than $k$ and determinately smaller than $m$ hangnails, according to the pleasure-theory, but not precisely equally as great as some number $n$ between $k$ and $m$. Or in other words, constructivism suggests the m-value facts aren't radically incomplete, but may not be fully complete either.

I suggested that one reason to explore axiomatisations of EVM without the Completeness condition is that many first-order axiologies aren't complete. But even if all axiologies under consideration are complete, at least under constructivism, there's another reason to do so. Under constructivism, plausibly, you may reasonably have credence in axiologies that aren't fully commensurable. And a representation theorem without the Completeness axiom would allow our argument to cover such axiologies. As indicated, we'll turn to that in Chapter 6. 